\title{
Development Characteristics and Genetic Analysis of Sand-bodies in Taiyuan Formation of Eastern Ordos Basin
}

\author{
Zhao Xiaohui", Liu Yan, Wang Yanqing, Jia Yani, Liu Wenxiang, Zhang Hui \\ Research Institute of Exploration and Development, Changqing Oilfield Company of CNPC, Xi'an, China
}

\section{Email address:}

zhaoxh_cq@petrochina.com.cn (Zhao Xiaohui)

${ }^{*}$ Corresponding author

\section{To cite this article:}

Zhao Xiaohui, Liu Yan, Wang Yanqing, Jia Yani, Liu Wenxiang, Zhang Hui. Development Characteristics and Genetic Analysis of Sand-bodies in Taiyuan Formation of Eastern Ordos Basin. Science Discovery. Vol. 7, No. 5, 2019, pp. 286-290. doi: 10.11648/j.sd.20190705.15

Received: August 22, 2019; Accepted: October 17, 2019; Published: October 23, 2019

\begin{abstract}
On the basis of fully understanding the regional geological background, the changes of lithology, bedding type and sedimentary facies sequence are analyzed according to core, logging and logging data。 The three sets of sandstones and their internal structural characteristics of Taiyuan Formation in Ordos Basin are defined. Qiaotou sandstone body is mainly developed in delta distributary channel, which is characterized by large thickness and wide distribution of sandstone body and multi-stage channel superimposition. Malan sandstone and Qiligou sandstone are mainly developed in submarine distributary channel of marine delta. They are relatively small in distribution scale, complex in internal structure of sand bodies, single massive sand bodies or composite sand bodies with thin mudstone interbeds. There are sand dams controlled by marine delta in Taiyuan Formation, which have different shapes and poor continuity. Based on the above results, it is considered that the sand body characteristics are mainly affected by paleo structuer topography, sedimentary environment and local uplift. These understandings are of great significance for judging the development position of high-quality reservoirs in sand bodies and improving the actual effect of oil and gas exploration and development in reservoir sand bodies.
\end{abstract}

Keywords: Taiyuan Formation, Sand-bodies Structure, Ordos Basin

\section{鄂尔多斯盆地太原组砂体结构特征及成因分析}

\section{赵小会", 刘燕, 王彦卿, 贾亚妮, 刘文香, 张辉}

中国石油长庆油田分公司勘探开发研究院, 西安, 中国

\section{邮箱}

zhaoxh_cq@petrochina.com.cn（赵小会）

摘要: 在对区域地质背景认识的基础上, 联合利用岩心、录井及测井等资料, 详细分析鄂尔多斯盆地太原组岩性、层 理类型及沉积相序变化, 明确了太原组发育的三套砂岩内部结构特征, 分析认为: 太原组桥头砂岩砂体主要发育于海 相三角洲分流河道, 砂体厚度大、分布广, 呈多期砂体叠加; 马兰砂岩和七里沟砂岩主要发育于海相三角洲水下分流 河道, 砂体分布规模局限, 砂体内部结构复杂, 呈单一块状砂体或具有薄层泥岩夹层的复合砂体。同时太原组局部发 育有障壁砂坝, 这些砂坝受海相三角洲控制, 形态各异, 连续性差; 基于以上分析认为太原组砂体特征主要受古构造 地形、局部隆起及海平面变化的影响, 这些认识对判断砂体中优质储层发育的位置, 提高储集砂体油气勘探与开发的 实效有重要意义。

关键词: 太原组, 砂体结构, 鄂尔多斯盆地 


\section{1. 引言}

鄂尔多斯盆地上古生界二叠统太原组储层发育的岩 性复杂, 沉积相变化快, 试气平均产量2万方/日以上, 是 勘探开发的重点层位, 目前在太原组提交的规模储量达 2000 亿方已成为神木气田提交储量的主力层系。但随着勘 探钻井密度的增加, 面临的地质问题也越来越复杂, 在钻 遇较厚砂体的周边常钻遇到砂厚较薄区, 这给井位部署及 下一步有利勘探区块预测带来较大挑战。太原组储集砂体 成因类型较多, 规模大小不等, 加上其成分、粒度及分选 等固有的特征及后期成岩作用的改造, 导致储集性能变化 大。因此从叠加样式、垂向结构及砂体成因的角度来研究 太原组砂体, 不仅有助于沉积环境的解释, 深化对储集砂 体的认识, 判断砂体中优质储层发育的位置, 并且可以提 高储集砂体油气勘探与开发的实效 [1]。本文将详细分析鄂 尔多斯盆地太原组砂体的沉积特征、砂体内部结构, 为研 究砂体分布规律及其成因提供重要素材, 以便拓展太原组 的勘探领域。

前人对鄂尔多斯盆地太原组沉积相做了大量研究并 取得了重要成果 [2-9], 认为太原组发育三角洲与潮坪交错 的沉积格局, 主要形成典型的辫状河海相三角洲沉积, 物 源方向决定了盆地北部三角洲相发育, 海侵过程中碎屑沉 积物北退, 海域发生碳酸盐沉积, 海退过程中三角洲沉积 向南逐步进积, 形成三角洲河道叠合沉积。整个太原期古 地理演化表现为早期海侵, 晚期海退的特点, 这种海侵一 海退变化直接影响就是在每次的海退阶段, 发育储集砂体, 海侵时期发育灰岩。沉积相研究已得到了学术界广泛认同, 并为本次研究建立了基础, 但太原组不同期次砂体内部特 征及造成这种砂体的原因分析涉及较少, 优势砂体的具体 层位有待进一步明确, 因此, 此项研究内容显得十分必要。

\section{2. 基本概况}

鄂尔多斯盆地是一个整体沉降、坳陷迁移、构造简单 的大型多旋回克拉通盆地。盆地上古生界太原组下伏于中 二叠系的山西组, 上覆于晚石炭系的本溪组, 均为整合接 触。总体上盆地北部砂岩发育, 南部灰岩发育; 下部碎屑 沉积发育, 上部灰岩发育。

太原组地层自下而上依次划分为庙沟段、毛儿沟段、 斜道段、东大窑段, 其中庙沟 (桥头砂岩) 段地层变化较 大, 毛儿沟 (马兰砂岩) 段、斜道 (七里沟砂岩) 段地层 相对稳定, 对应三套砂岩为桥头砂岩、马兰砂岩和七里沟 砂岩。岩相类型多, 以发育碎屑砂岩、泥晶生物灰岩、灰 黑一黑色泥岩、砂质泥岩为特征。在区域海侵、海退背景 下, 垂向上以砂岩、灰岩、煤层和泥岩等有规律地交替出 现, 地层剖面沉积序列出现陆相碎屑岩、煤层与浅海相灰 岩相互共存的海陆过渡相, 沉积旋回韵律十分清楚。

研究区 500 余个砂岩薄片的鉴定和统计分析表明，太 原组砂岩类型主要为中-粗粒岩屑石英砂岩, 占全部砂岩 样品的 $70 \%$, 其次为少量岩屑砂岩和石英砂岩。砂岩颗粒 主要为石英和岩屑, 少量长石, 颗粒之间孔隙式胶结, 以 点-线、线-线接触为主; 岩屑以变质岩和火山岩为主, 少
量沉积岩; 砂岩颗粒分选中等-好, 磨圆度主要呈次棱角 状至次圆状, 总体呈较高的成分及结构成熟度, 说明沉积 物是高能环境下沉积产物, 并具有较长时间水动力改造的 特点。

太原组砂岩储层主要为碳酸盐和粘土矿物胶结物, 其 中碳酸盐胶结物中铁白云石达 $2 \sim 5 \%$, 含量相对较高, 粘 土矿物中水云母含量尤其高, 绝对含量占 $10 \%$, 有的甚至 达 $15 \%$, 这也是鄂尔多斯盆地储层突出特色, 其次是硅质 胶结。碳酸盐胶结物和粘土矿物是引起太原组储集性能差 异性的主要原因; 太原组砂岩面孔率 $1.5 \sim 3.5 \%$, 以岩屑 溶孔为主, 马兰砂岩面孔率最好, 其次是桥头砂岩和七里 沟砂岩, 孔隙结构具有排驱压力高, 平均喉道半径和中值 半径小特点[10]。

\section{3. 砂体类型}

根据砂体的统计分析, 结合发育的沉积环境在南北向 上的对比及所受主控因素的不同, 得知太原组砂体储集体 主要为分流河道砂体、水下分流河道和砂坝。分流河道砂 体和水下分流河道砂体主要分布在盆地北部, 砂体纵向延 伸性较好, 横向连片性差, 砂体呈南北向展布, 决定了盆 地北部砂体的展布形态。砂坝主要位于盆地南部, 砂体规 模小, 连续性差。

\section{1. 分流河道砂体}

庙沟早期海平面上升, 海侵范围扩大, 盆地内主要沉 积碳酸盐岩, 庙沟期晚期随着海平面下降, 北部陆源碎屑 供给充足, 地表冲积水系与径流发育, 多条分流河道发育, 河道摆动迁移频繁, 此时发育的为桥头砂岩, 桥头砂岩是 三套砂岩中发育规模最大一套; 桥头砂岩三角洲平原分流 河道占优势相, 砂体规模较大, 古地形相对低洼 [11], 延 伸远, 四条砂带呈南北展布, 砂厚一般 $10 \sim 15 \mathrm{~m}$, 最厚达 $20 \mathrm{~m}$, 形成砂体巨厚多期透镜状叠置沉积, 在砂体的前端, 广泛发育舌状三角洲朵状, 河控特征显著。

桥头砂岩岩性以粗砂岩、含砾粗砂岩及中粗砂岩为主, 细砂岩和粉砂岩所占比例较少。沉积构造类型主要为块状 层理、平行层理、大型槽状及板状交错层理, 底部发育泥 砾, 冲刷结构特征, 反映水动力强。砂体内部粒度变化复 杂, 河道砂体紧密地叠置在一起, 呈厚层块状多期叠置型 砂体类型（图1A）, 勘探结果显示, 桥头砂岩虽是三套砂 岩中砂体最发育的, 但试气效果不是特别突出, 这与桥头 砂岩砂体厚, 但砂岩内部非均质性强有一定关系。

\section{2. 水下分流河道砂体}

毛儿沟早期海侵范围扩大, 晚期海退过程中发育马兰 砂岩; 太原组马兰砂岩主要发育于海相三角洲体系水下分 流河道砂体。大量的钻进岩心上观察到马兰砂岩 2 种沉积 特征, 其一砂岩内部结构相对均一, 夹层较少, 表现为单 块砂体, 这类砂体试气效果较好, 主要分布在双山地区, 是最早提交神木气田储量的关键砂体; 其二砂岩层系碳质 纹层富集, 砂体常出现泥岩、碳屑隔夹层; 整体上马兰砂 
岩表现为厚砂薄泥互层型模式 (图1B)。砂体厚度一般8～ $10 \mathrm{~m}$, 最厚达 $15.6 \mathrm{~m}$, 主要为一套细一中粗粒岩屑石英砂 岩, 垂向剖面上具明显的下粗上细的二元结构, 顶部细粒 沉积物发育, 被潮汐作用改造, 发育羽状交错层理。

斜道沉积期海平面上升最大，海侵入范围最广，在斜 道晚期海退, 发育太原组最后一套砂岩, 即七里沟砂岩, 七里沟砂岩河流一三角洲相向北部物源区退缩, 发育海相 三角洲体系水下分流河道砂体，该套砂体厚度 $5 \sim 20 \mathrm{~m}$, 神木及以北地区砂体发育。砂体厚度变化大，砂体间存在 非渗透性夹层, 沉积期泥质含量增多, 泥岩的隔夹层存在 导致复合河道砂体不均匀分布, 七里沟砂岩表现为厚砂与 薄砂、泥互层型（图1C）。分析认为七里沟砂岩内部非均 质性较马兰砂岩强, 砂体在盆地北部较发育, 气藏“小而 肥”, 试气钻井显示七里沟砂岩神木地区勘探效果较好。 七里沟砂岩主要发育一套灰色细一中粒岩屑石英砂岩, 沉 积层理上表现为块状构造、碳质纹层、泥质条带及菱铁矿 纹层, 显示三角洲前缘沉积相特征。
条件下受河道砂体的冲刷, 相互作用, 叠加改造, 最终呈 多种成因的砂坝, 研究区太原组波浪潮汐作用不是十分明 显, 砂坝主要表现为河流作用特征, 但岩心上也可以看出 这些砂岩粒度较粗, 成分成熟度和结构成熟度较高, 说明 确实被海水多次的改造, 最终砂坝内部结构微环境复杂, 具有向上变粗或向上变细的沉积序列, 代表了海退型沉积 演化序列或海进型沉积演化[12]。

在测井曲线上主要反响为光滑的箱状或者略带锯齿 的箱状, 砂坝主要发育灰色、浅灰色石英砂岩(图2), 物性 较好, 连续性差, 形状各异, 主要分布在盆地南部, 分布 范围很有限(图3)。太原组的钻探资料分析表明, 砂坝是勘 探的一个重要目标, 为了更好地研究砂坝的叠置关系及空 间展布特征, 在收集 8 口钻井砂厚数据基础上, 统计出砂 坝厚6-10m, 同时选取这 8 口井 70 多个物性数据点, 统计出 砂坝孔隙度平均为 $8.9 \%$, 渗透率平均为 $1.0 \mathrm{mD}$, 物性较好, 其中 shu 94 井试气获得2.3329万方/日的工业气流, 勘探成 果可喜。

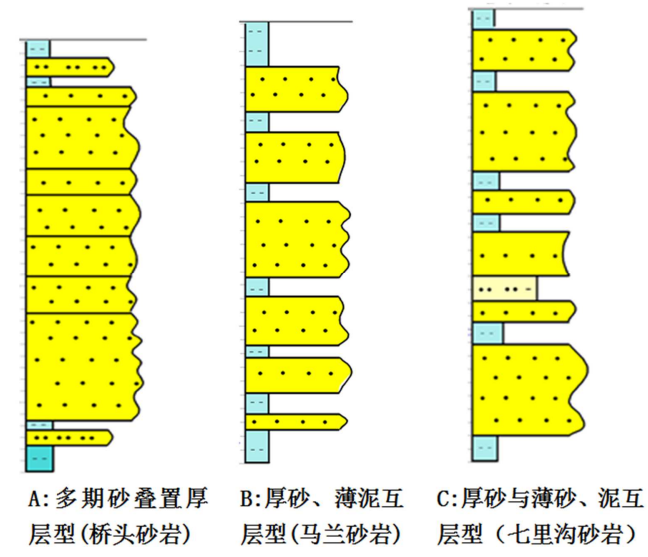

图1 太原组三套砂岩类型。

\section{3. 砂坝}

结合该区的沉积及储层特征, 受海相沉积环境的影响, 太原组不同期次的砂体发育障壁砂坝, 这种砂坝在水动力

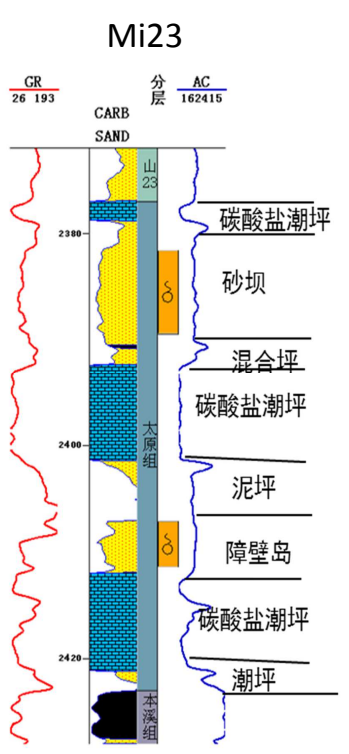

图2 Mi23砂坝沉积微相图。

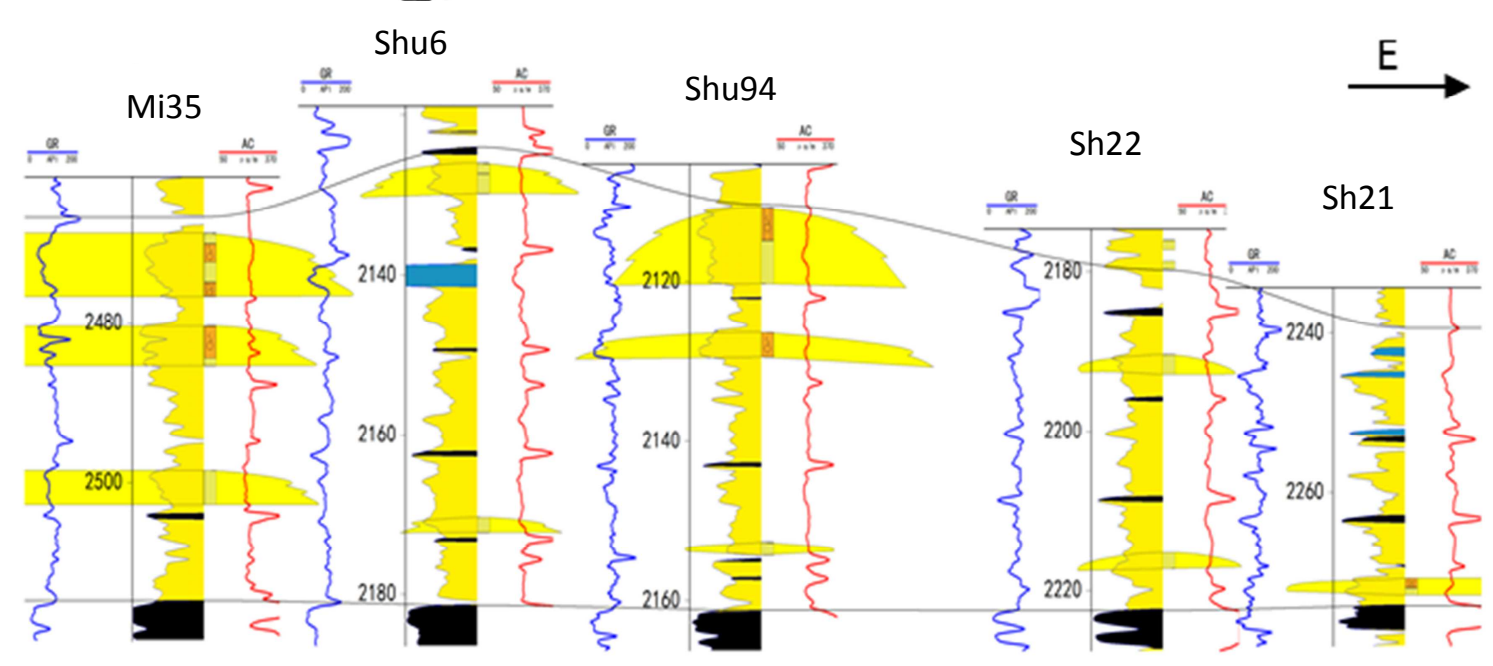

图3 鄂尔多斯盆地太原组砂坝展布。 


\section{4. 砂体内部结构}

成因砂岩研究是在综合单砂体和沉积微相两个研究 成果基础上开展的, 沉积环境、沉积相以及基准面升降旋 回是控制单砂体垂向结构、多层砂体垂向叠加样式及分布 的主要地质因素[13]。

砂体内部结构和测井曲线具有紧密响应的特征, 结合 实际资料井间精细对比分析, 桥头砂岩砂体一般发育 $1 \sim 3$ 个旋回, 这种叠加结构的砂体一般是沉积水动力持续较强 的河道型高能环境产物, 是三角洲中主分流河道微相的典 型反映, 也是对主分流河道微相在原地稳定持续沉积的响 应。单旋回厚度多在 $2.5 \sim 6 \mathrm{~m}$, 总厚度大; 测井曲线上表 现为自然伽马呈钟型、钟型和箱型的组合形式, 曲线底部 主要为突变形态, 向上渐变; 内部以正韵律为主, 发育复 合韵律, 隔夹层较少, 由于强水流的冲刷, 侵蚀而缺失,
造成上、下相邻的两个河道型砂体以冲刷面接触, 其间没 有明显可见的隔层或夹层。

马兰砂岩砂体一般发育 $1 \sim 3$ 个旋回, 长短不一, 测井 曲线上以箱型与钟型组合为主，同时钟型、漏斗型的叠加 组合及齿化的箱型也常见; 箱型隔夹层较少, 砂体内部结 构相对均一, 这类砂体泥质含量较少, 连通性好, 是储层 发育的有利部位; 另外一种是上部具有漏斗结构叠加下部 齿化箱状结构的分流河道砂体, 这种叠加结构储层砂岩粒 度变化复杂, 非均质性较强。

七里沟砂岩一般发育2 5个旋回, 测井曲线形态多样, 自然伽马曲线呈钟型、钟型和箱型叠加, 砂体内部粒度变 化快，上、下相邻砂体之间多有厚度不等的泥质隔、夹层， 连通性不好, 甚至是不连通的, 砂体被泥岩薄层完全隔开, 表现出非均质性强的特点, 岩性较细, 泥质含量较高, 具 有明显的高伽玛起伏形态（图4）。

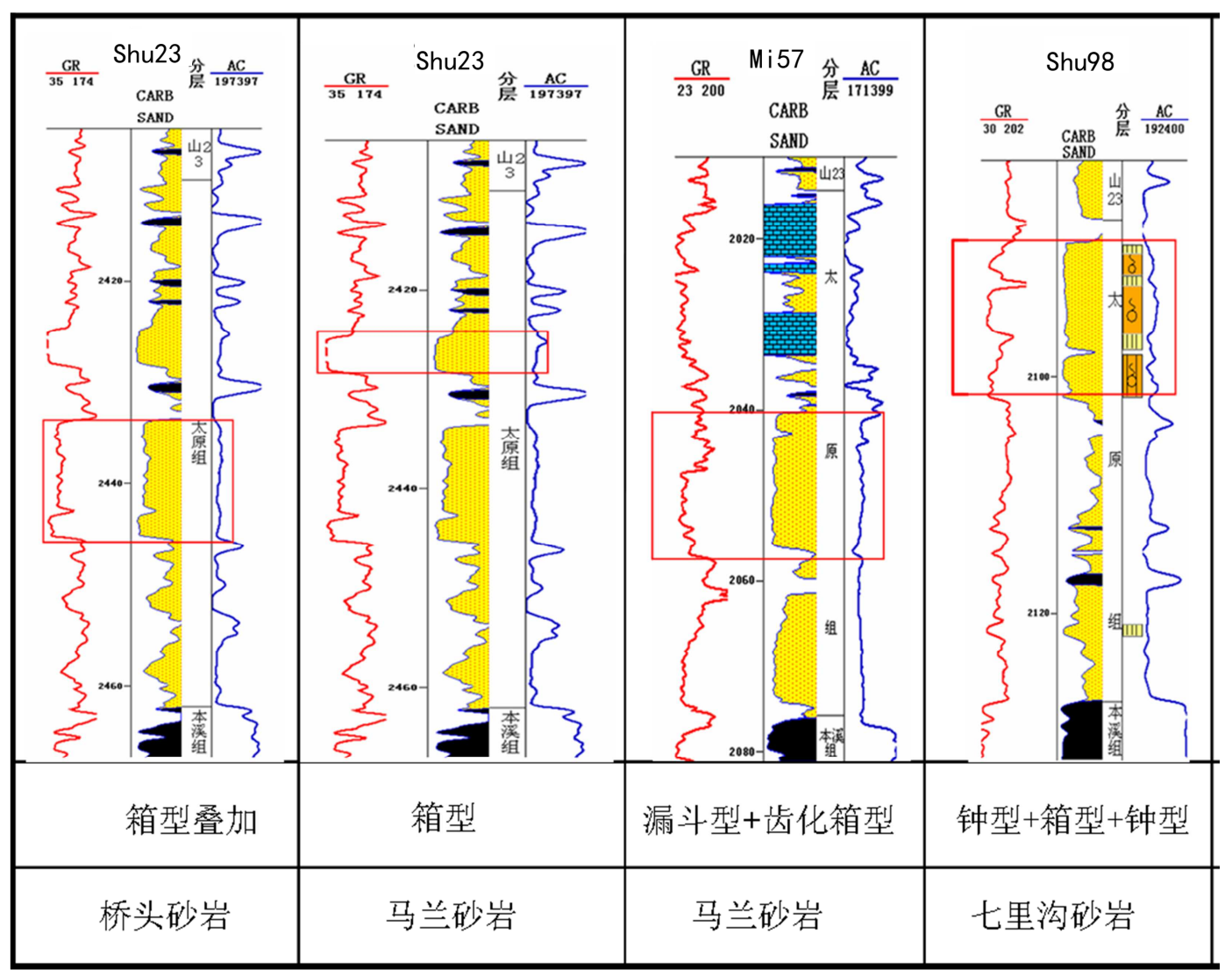

图4 鄂尔多斯盆地太原组砂体结构类型。

\section{5. 控制砂体主要因素分析}

\section{1. 古地形条件}

晚古生代由于受到盆地北缘兴蒙海槽、南缘秦祁海槽 的俯冲和挤压作用, 太原期鄂尔多斯盆地具有北高南低、 西高东低地势特征 [14], 此时祁连海和华北海域连通, 海 侵自东南方向侵入，随着盆地北部的陆源碎屑不断地涌入 盆地内, 使得该区三角洲平原相的分流河道和三角洲前缘 的水下分流河道砂体发育 [15], 在研究区东南部形成障壁
岛砂坝。在填平补齐的沉积作用下地形起伏变化引起砂体 规模变化, 太原组三套砂岩沉积展布范围变化差异大, 庙 沟晚期盆地北部的陆源碎屑向盆内进积, 桥头砂岩作为太 原组第一期沉积砂体, 受古地形影响最明显, 砂体发育厚 度不均, 在最厚处达 $40 \mathrm{~m}$ 。

\section{2. 局部隆起}

局部的隆起部位在海侵作用下，易于引起海水能量 突然的变化, 当波浪或潮汐触及地面, 发育障壁砂坝, 因此在沿着海侵方向的局部隆起部位附近是砂坝发育区; 
太原组这种砂坝认为主砂体带期沿海侵的东南方向有障 壁砂坝沉积, 在后期河流作用占主导时发育的三角洲分 流河道极有可能直接侵蚀沉积于早期砂坝之上。以 sh27-mi12-mi57-yu12连井剖面为例, mi57处于隆起部位, $\mathrm{sh} 27$ 到 $\mathrm{mi} 57$ 两者相距 $18.9 \mathrm{~km}$, 经压实校正后地形坡降为 $0.05 \mathrm{~m} / \mathrm{Km}, \mathrm{mi} 57$ 与yu 12 两者相距 $15.3 \mathrm{~km}$, 经压实校正地 形坡降为 $0.65 \mathrm{~m} / \mathrm{km}, \mathrm{mi} 57$ 井位于隆起部位这是障壁砂坝 发生的一个重要因素。钻井资料显示, 该井太原组岩性 为石英砂岩, 颗粒分选和磨圆度均较好, 孔隙度平均为 $9.6 \%$, 渗透率平均为 $0.89 \mathrm{mD}$, 因此局部隆起易于产生砂 坝。

\section{3. 海平面升降}

沉积相带的展布控制了砂体与砂岩类型的空间展布 及其分布规律 [16], 随着海平面的周期性变化, 沉积体系 的类型和配置引起砂体类型不同, 太原期完整的经历了 四次海平面的升降，对应发育庙沟期、毛儿沟期、斜道 期和东大窑期四套灰岩和桥头砂岩、马兰砂岩和七里沟 砂岩三套砂岩沉积体系, 造成三套砂岩内部沉积结构不 同, 在缓慢海退过程中逐渐过渡海相三角洲沉积; 海水 作用弱的地区, 三角洲沉积体系占优势, 表现为分流河 道和水下分流河道砂体发育, 连续性好, 厚度大的复合 叠加, 在海水作用强的地区波浪潮汐作用下, 砂坝发育, 表现为砂体分选好, 连续性差, 规模有限, 因此太原组 砂体是在受海平面升降变化影响下发育的三角洲河道砂 体和砂坝砂体。

\section{6. 结论}

通过结合岩心、录井及测井等资料, 得出太原组沉积 相及砂体内部变化特征认为:鄂尔多斯盆地太原组桥头砂 岩发育三角洲分流河道特征, 砂体具有南北向延伸远, 条 带状展布, 厚度大、平面连片分布, 砂体厚度不稳定, 变 化较大特征, 砂体内部粒度变化频繁, 表现多期砂体叠置 型; 马兰砂岩主要发育三角洲水下分流河道, 规模相对较 小, 条带状展布, 砂体内部呈单一块状砂体或具有泥岩夹 层的复合砂体，表现为厚砂薄泥型。七里沟砂岩主要发育 三角洲水下分流河道, 分布规模相对较小, 砂体内部主要 表现为厚砂、薄砂及泥岩互层型特点。

依据沉积演化特征, 分析出太原组发育的主要砂体为 海相三角洲分流河道砂体、水下分流河道砂体及改造后的 砂坝, 同时这些砂体分布规律主要受古构造地形、局部隆 起和海平面变化的影响。

根据砂体沉积微相-测井相-非均质性-试气成果特征 分析, 马兰砂岩在双山一带储层岩性物性特征好, 具有中 等非均质性; 七里沟砂岩在盆地北部神木区块砂体厚度大, 相对稳定, 储层非均质性强; 这两块试气成果好, 是勘探 开发中的优质砂体。

\section{参考文献}

[1] 赵云翔, 陈景山, 王建峰等. 鄂尔多斯盆地延长组长 9 砂 体的垂向结构及主控因素分析[J].沉积学报, 2013, 31 (1): $77-88$ 。

[2] 李晓路, 于兴河, 谭程鹏, 等.潮汕地区全新世障壁海岸三 角洲沉积演化与砂体展布 [J].沉积学报, 2015,3(4): 706-712。

[3] 沈玉林, 郭英海, 李壮福, 等.鄂尔多斯盆地东缘本溪组太原组层序地层特征 [J]. 地球学报, 2009,30 (2)：187-193。

[4] 兰朝利, 张君峰, 陶维详, 等.鄂尔多斯盆地神木气田太原 组沉积特征与演化 [J].地质学报, 2011,85 (4)：533-541。

[5] 屈红军,马 强, 高胜利.物源与沉积相对鄂尔多斯盆地东南 部上古生界砂体展布的控制[J].沉积学报, 2011, 29（5）: 825-834。

[6] 刘再振,刘玉明,李洋冰,等.鄂尔多斯盆地神府地区太原组致 密砂岩储层特征及成岩演化 [J]. 岩性油气藏, 2017, 29(6): $51-59$ 。

[7] 陈昭佑,王光强. 鄂尔多斯盆地大牛地气田山西组砂体组合 类型及成因模式 $[\mathrm{J}]$. 石油与天然气地质, 2010, 31（5）: 630-639。

[8] 王卫红, 田景春, 王峰.鄂尔多斯盆地太原组煤层形成环境 及分布特征研究 $[\mathrm{J}]$, 煤炭技术, 2016，35（6）：125-126。

[9] 陈义林, 李壮福, 秦勇.鄂尔多斯盆地双山地区太原组砂岩 次生孔隙形成机制 [J], 煤田地质与勘探, 2011，39（1）: 11-15。

[10] 柳娜, 姚宜同, 南珺祥, 等.鄂尔多斯盆地东部盒 8 段、太 原组织米砂岩储层特征及低产因素 [J], 成都理工大学, 2015, 42 (4) : 435-443。

[11] 平立华, 郭英海, 李壮福, 等.鄂尔多斯盆地保德地区太原 组桥头砂岩沉积特征及成因 [J]. 天然气地球科学, 2006,17 (6) :797-801。

[12] 杨辰雨, 田景春, 张翔, 等. 基于砂体构型精细刻画潮坪 砂坝优质砂体 [J], 石油与天然气地质, 2015, 36(2): 248-254。

[13] 方小宇 河流相储层建筑结构及流动单元研究[J]. 重庆科技 学院, 2006, 8(1): 14-17。

[14] 郭军, 陈洪德, 王峰, 等.鄂尔多斯盆地太原组砂体展布主 控因素 $[\mathrm{J}]$, 断块油气田, 2012，19（5）：568-571。

[15] 郭 军, 陈洪德,苏中堂. 鄂尔多斯盆地中央古隆起对太原组 砂体发育的控制作用 [J], 天然气勘探与开发, 2014, 37(2): 5-9。

[16] 罗静兰, 魏新善, 姚泾利, 等.物源与沉积相对鄂尔多斯盆 地北部上古生界天然气优质储层的控制 [J], 地质通报, 2010, 29 (6) : 811-820。 